\title{
THE ART OF DOMINATING IN SOCCER PLAY
}

\author{
Gabriel MANOLACHE \\ „Dunărea de Jos” University of Galaţi, \\ gabmanolo@yahoo.com
}

\begin{abstract}
During the game the cognitive processes underlying decision making, both in attack and in defense, tactical skills, positioning players, occupying various positions, anticipating the opponent phases and movement are essential to victory. In soccer and not only, results are often the best indicator of a team's performance but insufficient to a coach to assess his team performance.Video analysis, interpretation play on this method but a means of training comes and creates capacity for adaptation and response team and players from different areas and different football game The more information the player gets during training, in the meeting room and thisrepeats each day, the more he becomes aware of what he has to do in the field. If video images are perceived in the beginning (9-10 years) as motivating images for a particular execution and its correctness, then the same video and video analysis (if we speak about individual and individualization) can be used to better perceive the tactical position which he has to adopt on a certain stage of the game.
\end{abstract}

Key words: video analysis, skills, tactical shape, interpretations the play, methods.

Often, identifying the talent of every child entering the football stadium is increasingly difficult, and not only because of the rigors of football or the "preparation steps" that need to be made by each participant at this wonderful sport. But due to the changes in society that we are part of, like advanced technology, increased sedentarism, exaggerated claims, primarily at the level of parents, less work, less sweating. When I talk about technology, I would love to use it to the advantage of children and juniors. Being aware of each move, and to compare the player with the model that he has, or how, where he had to be at a particular moment of the game, are tactical precepts that must be used in the training of young footballers.

These hours of training on the field, butalsoin the locker where the images can take the place of the long explanations, can become very important or capital for the young player. When do these analysis, and do pictures occur/appear or are shown ? The coach experience shows me that at the age of 14-15, you are aware of your movement and your teammates on certain phases of the game, in attack or defenseit becomes capital / essential / very important in the conscious formation of the performer to be. Informing the player permanently and preparing him from a tactical point of view can become a "methodical step" at one point, but the great art at the juvenile level is the technical tactical preparation, that is to say the tactical value of each element or technical process. It is very important how you hit the ball but also where you send it, to cover through the 10 players of the field surface field in each phase of the game, not only the physical training but also the awareness of the positions that each player has to respect according to the position of the ball, teammates or opponents many times. The battle goes into winning before the ball gets different positions in the field. All this is taught like kicking or taking over the ball. This is why, after the age of 14-15, the elements of the game without the ball become important and to be developed, they must be well trained at first.

Each player has or fulfils a role in the field, a role, a position on the defensive phase and a role or position on the offensive phase, there are no players who only evolve in attack or defense, so they have to be educated, trained, raised, developed young players if we talk about football performance. Each player has an "area" in which he / she has to play the role of defender or striker depending on the position of the ball and the movement of his / her own opponents. So, considering the different types of characteristics for different areas, they learn and consolidate over time, through field training, but also by viewing them, recording them and repeating them, which can determine at some point automatism of movement and interpretation of the game, common, collective, tactical moves that either cause the ball to recover, or trigger attacks or repellents on ball recovery areas. Regardless of how aware of the position of the ball, the speed of the ball transmission, the speed of demarcation of the players, football has and will be based on balloon control and the more it will correlate with the information about the position of the players in the field, the distance from gate, the more the awareness of attacking or defending action will become a lethal "gun" against the adverse team. Today it is not so important to control the ball but to control it in speed and move it quickly in front of the goal to score.

Video images are presented to juniors in the first place to get acquainted with the patience to look, understand, transmit some knowledge of what they have to do in the field. First of all, the technique is a priority 
and we need to help of the models presented.As gradually with the aging, but also in the accumulated football experience, the tactics becomes pryorities. Today more than ever the player's intelligence is used to the maximum and this intelligence also comes from the awareness of the good or less good methodical work done in the training. It is the "tool" of the coach to correct himself if he has mistaken/misjudge in the appreciation of a phase, or even a player.

Video analysis can be excellent feedback from one workout to another. National junior teams have very little time to prepare together (to us 3-4 days) showing in the pictures what you will do is more useful than to explain them for 15 minutes. This placement in the field, the positioning of the players on certain phases of the football game becomes very important. So video analysis becomes a strategic weapon in addressing international games.It is therefore very important for each player to consider the following:

-the position in which he receives the ball, he trains but becomes aware of it until it becomes automatism;

-where he got the ball into the field;

- what is the position of the opponents in the field, especially the distances between them;

-how he or she can use/ not use the space in which he is, but also the ball he or she may or may not transmit;

-correlation of these time / space elements / verbal and nonverbal communication with the moment of the game and the score at that time.

Purpose:developing the programme to videoanalytical work, twice the day, 12 minute after the training, three weeks before the start of the tournament, competition.

Tasks: Introduce and apply research methods, monitor and record the position of players in the defense phase in the first place to plan the attachment preparation procedure after the recovery of the ball, the area where we do it, to train that and to set in the foreground the results.

\section{Hypotheses of the research:}

- we assume that improving video image training (what we do on every level of landing where when we don't have the ball)

- before training / match and after training / joint match has an influence on the positioning and the game in a certain area of land - recovery of the ball;

Method and procedures: During the study we used the following research methods: the bibliographic method, the observation method, the experimental methods and the statistical-mathematical methods of graphical representation of the results.

The stages of the research : - study of the bibliographic material and the establishment of the work, - selection of the most representative phases of the offensive game, defensive play, launching phase, organization and conduct of the video activities; - the processing and interpretation of the data from the observing the video of the opponent's game and their our training; - establishing the conclusions and recommendations given to the players.
The study and subjects: The study was conducted on a Romanian "U" 16 soccer players duringU.E.F.A. Tournament of Development in Bulgaria,15th-20thMarch 2016, a team which includes 18 players aged between 14 and 15 years, over a period of 3 weeks.

Working Strategies: I established a work program where the team has 12 minutes of video view and analysis, twice before and after training, every day. The program was the following - The standard daytime viewing program - 12 minutes with defenders and midfielders, and in the afternoon 12 minutes with strikers and midfielders.

\section{Objectives}

1. To put up the basis of a consciuos preparation/training and active concentration and attention on the moments of the game without the ball through our position in our field area.

2. The involvement of my players in understanding / awareness of what they have to do in the defense phase, the recovery of the ball and the rapid switching from attack to/or fast attack.

3. Fast switching from the attack and defense to be done in an organized way, on certain in areas of the field/field to put the opponent in difficulty if he remains in your field area.

4. Watching/viewing these results to create a positive emotional transfer on the team, that can be looked on the marking table by the game marking and the time that the opponent has moved and what zones which would not give that difficulty in our gate.

Results of the research: Study and application of a video program methodology in the process of 14-15 years in the international area to identify a first step in mental training for young players. The determination of the position which must be given and an application to a certain moment of the game confirmed confidence in our own force when we have possession of the ball. The results of the research showed that the assumed position of our opponents determined us the recover more back to the middle of the field from where we started the rapid attacks which meant the goals in the opponent's gate and the video analysis helped the 14-15 years group to accomplish the performance's objectives for this age.

Weekly schedule:-video-analysis three weeks before Tournament. 
Tabel 1. Training video-analysis

\begin{tabular}{|c|c|c|c|c|c|}
\hline Monday & Tuesday & Wednesaday & Thurday & Friday & Saturday \\
\hline $\begin{array}{l}12 \text { minutes } \\
\text { video- } \\
\text { analysis } \\
\text { before } \\
\text { training } \\
\text {-complete } \\
\text { team training }\end{array}$ & & $\begin{array}{l}12 \text { minutes } \\
\text { video-analysis } \\
\text { before training } \\
\text {-complete } \\
\text { team training }\end{array}$ & $\begin{array}{l}12 \text { minutes } \\
\text { video- } \\
\text { analysis } \\
\text { before } \\
\text { training } \\
\text {-complete } \\
\text { team training }\end{array}$ & $\begin{array}{l}12 \text { minutes } \\
\text { video- } \\
\text { analysis } \\
\text { before } \\
\text { training } \\
\text {-complete } \\
\text { team training }\end{array}$ & Match play \\
\hline Afternoon & Afternoon & Afternoon & Afternoon & Afternoon & Afternoon \\
\hline $\begin{array}{l}\text {-individual } \\
\text { training } \\
12 \text { minutes } \\
\text { after training }\end{array}$ & $\begin{array}{l}\text {-training } \\
\text { compartments } \\
\text { of the game. } \\
\text { 12minutes } \\
\text { after training }\end{array}$ & $\begin{array}{l}\text {-individual } \\
\text { training } \\
\text { 12minutes } \\
\text { after training }\end{array}$ & $\begin{array}{l}\text {--training } \\
\text { compartments } \\
\text { of the game. } \\
\text { 12minutes } \\
\text { after training }\end{array}$ & $\begin{array}{l}\text {-individual } \\
\text { training } \\
12 \text { minutes } \\
\text { after training }\end{array}$ & \\
\hline
\end{tabular}

These video analysis allows us to do technicaltactical corrections higher in the position of player on certain phases of play which means that we can determine the young players to have more considerations in their mental preparations. That is why I cannot say that we correct technically certain elements but we are conscious about the correct execution of the exercises/move and especially on the precis time.
During those three games were recorded following statistics, Romania has over 200 stages atta offensive and defensive of which 86 phases to u place other half, meaning $43 \%$ of them found the Romanian team in attack

Also in this tournament we had 35 pieces of which 20 were only opposing goal meaning $54 \%$ of these phases. (Chart 1)

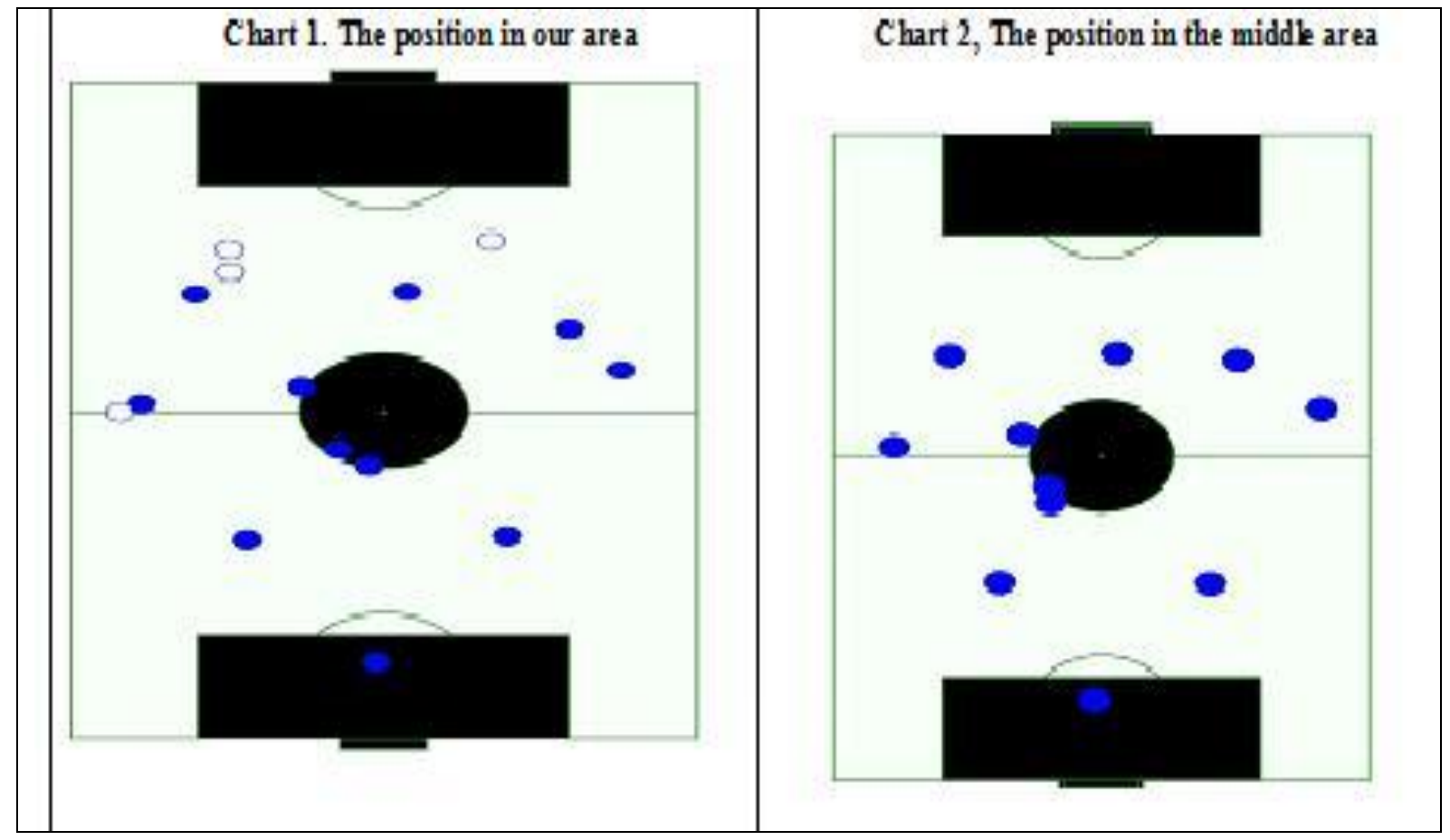

After the first game position players was not quite the best, especially in the middle of the area but I wanted to recover the ball. (Chart 2). After four video analysis and training for another day -Wednesday -see Table 1- in the second match players werein the correct middle position (Chart 3). 
Chart 3. The corect position in the our area

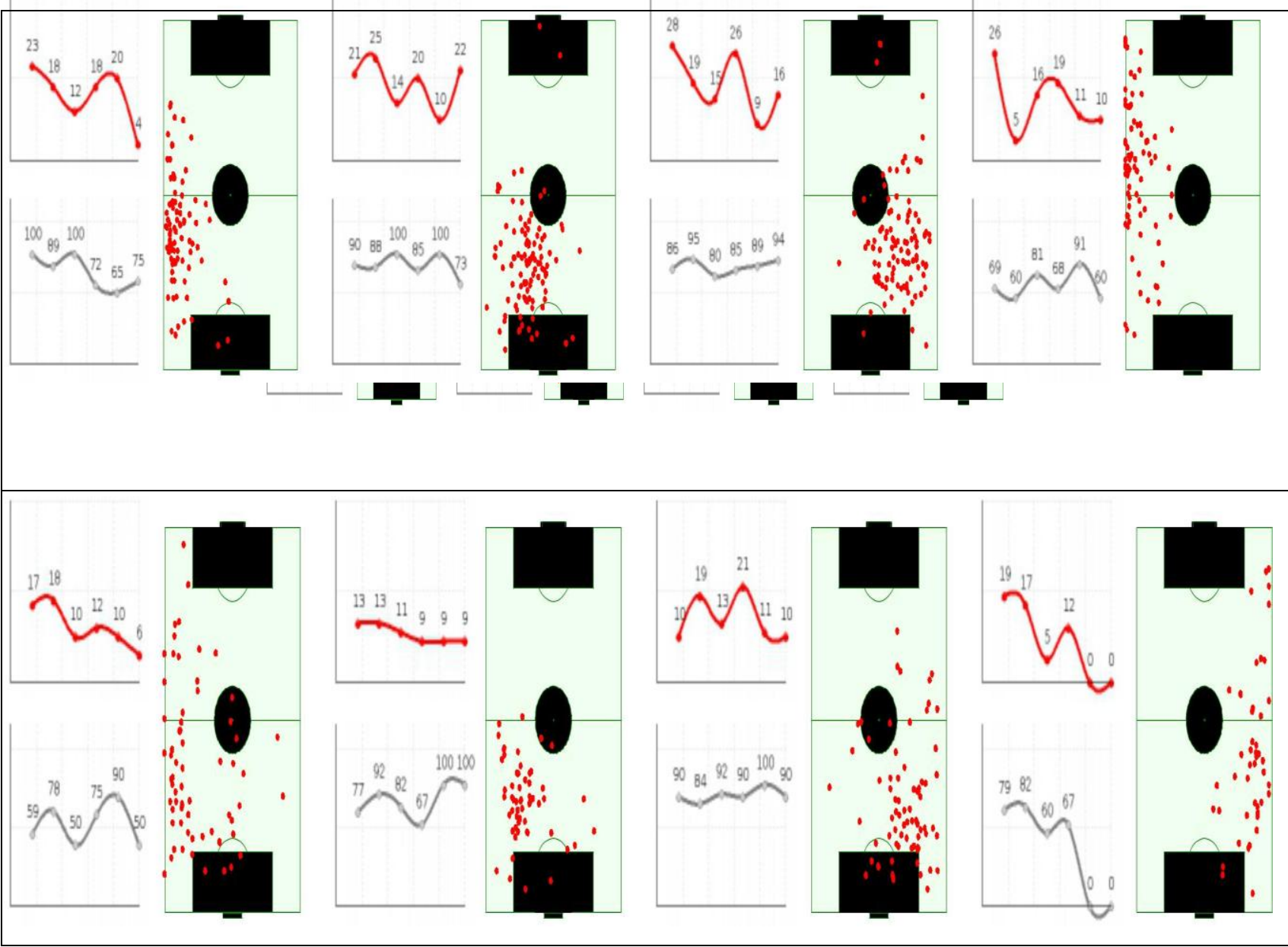

A final analysis of the competition played after five days of playing and coaching team of Romania "U"16 is good in some areas of offensive game other half (Chart 4).

Chart 4. Analysis tactical

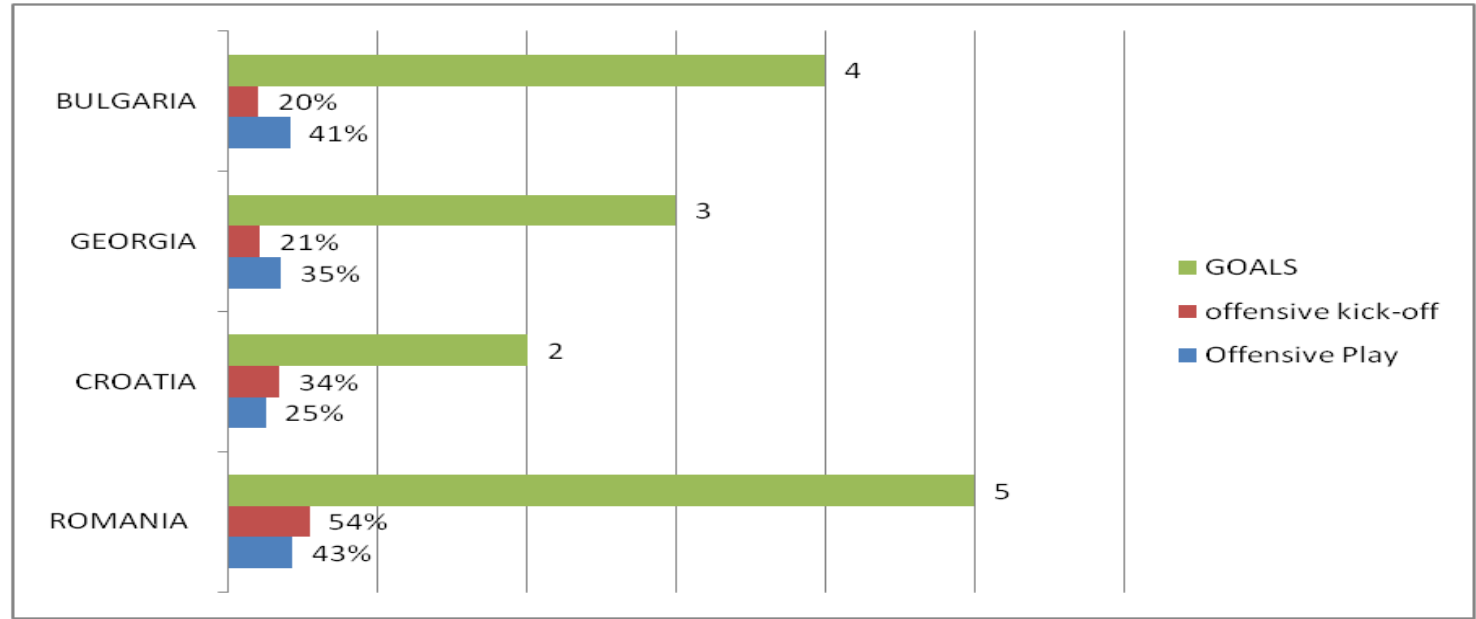

\section{Conclusion}

Preparing a young football player, physically, but especially mentally, is much more important, the football competition needs an 18 -year-old to judge as a 40 -year- old mature. So these video interpretations, their awareness should be practised in training sessions, not only at official games, from basic exercises - if we consider their correctness - but also in more advanced tactical exercises. 
The player in the demarcation informs himself about his position, how, where he receives, and especially how he takes the ball because he needs to be aware of: -position to the opposing gate-with the face to it; -the space I have or not given by the opponent;

- where to take over or where to take the pass after recovering the ball-looking for free space.

When the player has the ball, hemust do the following:

- facing the opponent's goal;

-the distance until the opponent's goal;

- how the opponents are placed against their gate;

- first touch.

Important in football are those two possible moments, possession or no possession, what can my football players do with their space and time? Video analysis determined the qualities and flawsof an opponent on these phases-moments of the game. It is important to make your football players aware of their own expression level.
The technical advice recognizes these characteristics of the opponents, but they need to make their own football players used to this kind of meetings, their importance and the role of every player in the team. Having hereby recognized these characteristics of the adversaries.

\section{References}

1.www.uefa.com/Devolpment Youngs Players Tournament; 2.Taylor JB, Stephen DM, Nic J., "Behavioural comparisons of positional demands in professional soccer". Journal Perform Anal Sport 2004.

3.Hubert K., Bernt S.,Soeffner H., "Video-analysisMethodology and Method", Ed.Offprint,2006.

4.Aboutoihi, S. Football: Guide de L'éducateur Sportif. Paris: Editions ACTIO. 2006. 